\section{Drug-Eluting Stents vs Bypass Surgery for Unprotected Left Main Disease}

\section{To the Editor:}

We read with great interest the study by Shimizu et al of coronary artery bypass grafting (CABG) vs percutaneous coronary intervention (PCI) with drug-eluting stents (DES) for unprotected left main coronary artery (ULMCA) disease. ${ }^{1}$ Regrettably, no statistical adjustment for potential confounding was applied in their study, despite it being nonrandomized and retrospective. Our recent meta-analysis ${ }^{2}$ combining adjusted hazard ratios (HRs) from 7 qualifying observational studies (2,841 patients) suggested that PCI with stents might increase late (2- to 4-year) mortality relative to $\mathrm{CABG}$ in patients with ULMCA disease (HR, 1.35; 95\% confidence interval (CI), 1.04 to $1.75 ; \mathrm{P}=0.02$ ). In several studies analyzed in the meta-analysis, however, the stent group included patients receiving bare-metal stents (BMS). We herein would like to perform a meta-analysis of comparative studies of PCI with exclusive DES vs CABG for prevention of late mortality in ULMCA disease.

To identify all comparative studies of PCI with DES vs CABG enrolling patients with ULMCA disease, public domain databases including MEDLINE, EMBASE, and the Cochrane Central Register of Controlled Trials were searched (current through April 2010) using Web-based search engines (PubMed, OVID). Studies considered for inclusion met the following criteria: the design was a comparative study; the study population was patients with ULMCA disease; patients were assigned to PCI with DES vs CABG (on-pump or offpump); and main outcomes included adjusted (in case of observational studies) HRs for late ( $\geq 1$ year) all-cause death. Our search identified 5 qualifying observational studies providing adjusted HRs in 2- to 5-year follow-up. We excluded 2 randomized trials, because $65 \%$ of patients received BMS in the trial by Buszman et al, ${ }^{3}$ and the SYNTAX trial ${ }^{4}$ enrolled patients with multivessel but not ULMCA disease. Pooled analysis $(1,889$ patients) demonstrated a statistically nonsignificant increase in mortality with PCI using DES relative to CABG in the fixed-effects model (Figure: HR, 1.24; 95\%CI, 0.93 to $1.65 ; \mathrm{P}=0.14)$. There was minimal between-study heterogeneity ( $\mathrm{P}=0.36$ by standard $\chi^{2}$ tests), and accordingly little difference in the pooled result from random-effects modeling ( $\mathrm{HR}, 1.24 ; 95 \% \mathrm{CI}, 0.91$ to $1.68 ; \mathrm{P}=0.17$ ). Exclusion of any single study from the analysis did not substantively alter the overall result of our analysis. There was no evidence of significant publication bias $(\mathrm{P}=0.62$ by an adjusted rankcorrelation test).

The results of our analysis suggest no significant differences in midterm (2- to 5-year) mortality between PCI with DES and CABG in patients with ULMCA disease. Although our previous meta-analysis ${ }^{2}$ demonstrated a significant benefit of CABG over PCI with DES/BMS, DES may improve midterm mortality compared with BMS in ULMCA disease.

\section{References}

1. Shimizu T, Ohno T, Ando J, Fujita H, Nagai R, Motomura N, et al. Mid-term results and costs of coronary artery bypass vs drug-eluting stents for unprotected left main coronary artery disease. Circ J 2010; 74: 449-455.

2. Takagi H, Matsui M, Umemoto T. Increased late mortality with percutaneous stenting for unprotected left main coronary artery stenosis relative to coronary artery bypass grafting: A meta-analysis of observational studies. J Thorac Cardiovasc Surg 2010; 139: $1351-1353$

3. Buszman PE, Kiesz SR, Bochenek A, Peszek-Przybyla E, Szkrobka I, Debinski M, et al. Acute and late outcomes of unprotected left main stenting in comparison with surgical revascularization. $J$ Am Coll Cardiol 2008; 51: 538-545.

4. Serruys PW, Morice MC, Kappetein AP, Colombo A, Holmes DR, Mack MJ, et al. Percutaneous coronary intervention versus coronaryartery bypass grafting for severe coronary artery disease. $N$ Engl J Med 2009; 360: $961-972$.

Hisato Takagi, MD, $\mathrm{PhD}$

Takuya Umemoto, MD, PhD

Department of Cardiovascular Surgery, Shizuoka Medical Center, Shizuoka, Japan

(Released online August 6, 2010)

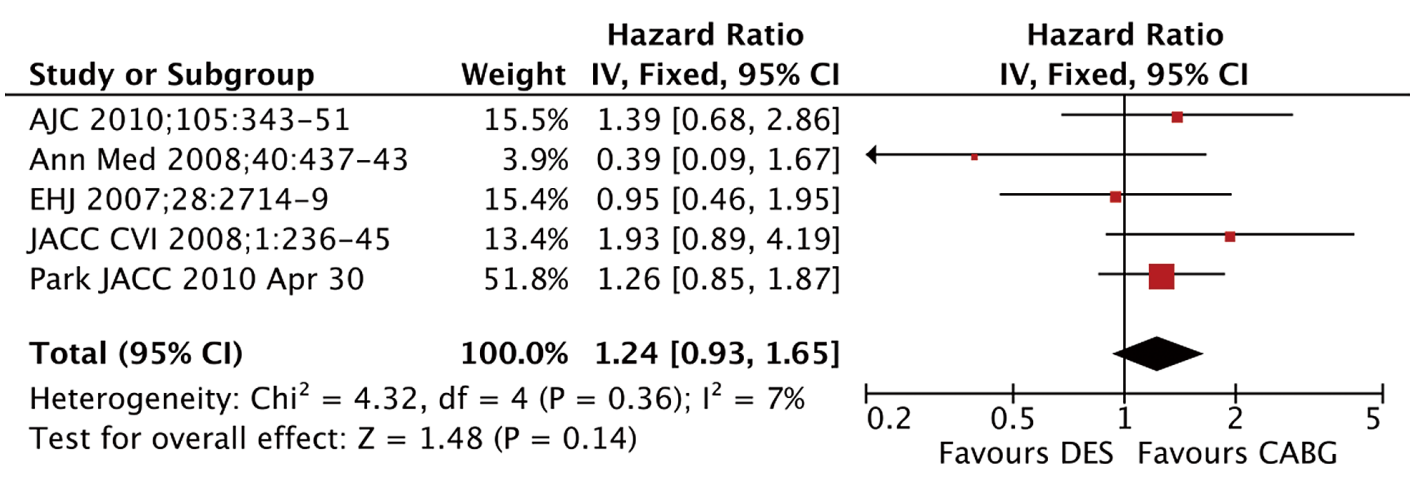

Figure. Follow-up mortality among patients with unprotected left main coronary artery disease assigned to percutaneous coronary intervention with drug-eluting stents (DES) vs coronary artery bypass grafting (CABG). AJC, American Journal of Cardiology; CI, confidence interval; JACC, Journal of the American College of Cardiology; JACC CVI, JACC Cardiovascular Intervention; EHJ, European Heart Journal; IV, inverse variance. 